\title{
Racial Battle Fatigue, Epistemic Exploitation and
}

\author{
Willful Ignorance: \\ "Why I'm No Longer Talking to White People about Race." \\ Barbara Applebaum \\ Syracuse University
}

Racial battle fatigue (RBF), the ubiquitous "physiological, psychological and behavioral strain exacted on racially marginalized and stigmatized groups and the amount of energy they expend coping with and fighting against racism," ${ }^{1}$ has become the pervasively quotidian experience of faculty, students, and staff of color on predominantly white university campuses. Research studying the experiences of students of color who endure microaggressions makes it abundantly clear that RBF is not only a product of blatantly obvious insults and invectives but of the cumulative and subtle assaults that are both unrelenting and also ambiguous, and thus difficult to name and confirm for those who do not experience such indignities. The resulting emotional turmoil, frustrations, anger, and other serious physical and psychological consequences that affect the lives of students of color and their educational experience have been well-documented. ${ }^{2}$

Building on the recent research in the area of epistemic injustice, this paper focuses on the epistemological costs of RBF for students and faculty of color on predominantly white college campuses that "diminish a person's capacity as a knower to generate and participate in making knowledge claims" and accentuates the role that willful ignorance plays in such harms. In what follows, I briefly describe the two types of epistemic injustice as introduced by Miranda Fricker ${ }^{4}$ and highlight how critics have expanded and revised her arguments by directing attention to a third type of epistemic injustice, contributory injustice, that emphasizes the role that willful ignorance plays in protecting dominant frameworks of intelligibility from challenge. 
Attending to willful ignorance helps us to better articulate the epistemic harms that the epistemically marginalized endure. Epistemic exploitation, a concept introduced by Nora Berenstain, ${ }^{5}$ provides a compelling illustration of willful ignorance and its damaging consequences that exacerbate RBF. Some epistemic effects of willful ignorance are examined as well as the choice to withdraw from conversation with white people. Finally, some concrete classroom discussions around safe space that can be informed by understanding the epistemic harms of willful ignorance are discussed.

\section{EPISTEMIC INJUSTICE}

In her widely cited book, Epistemic Injustice: Power and the Ethics of Knowing, Miranda Fricker coins the term "epistemic injustice" to address the ways in which members of marginalized groups are not justly treated as epistemic agents. There is a distinctively epistemic type of injustice in which someone is wronged specifically in their capacity as a knower. The idea of epistemic injustice highlights the mutual entanglement of ethics and epistemology that earlier trailblazing feminist philosophers pioneered, themselves targets of the very epistemic marginalization that Fricker describes. ${ }^{6}$

Fricker identifies two types of epistemic injustice: testimonial injustice and hermeneutical injustice. Testimonial injustice occurs when "prejudice causes a hearer to give a deflated level of credibility to a speaker's word"7 or when an individual's expression of knowledge is granted less credibility due to factors such as race, gender, or other markers of marginalized social identity, what today is often referred to as implicit bias. Hermeneutical injustice occurs when the collective hermeneutical resources are shaped by the experiences of dominantly situated knowers so that a lacuna or gap in the collective conceptual resources, according to Fricker, makes it difficult for the marginalized to understand their own experiences. In both cases of testimonial and hermeneutical injustice, the person's capacity as an epistemic agent is jeopardized because one's ability to share knowledge with others is unjustly diminished.

One of the illustrations of testimonial injustice that Fricker provides 
concerns the trial of Tom Robinson, drawn from Harper Lee's To Kill a Mockingbird, ${ }^{8}$ in which the jury does not perceive the testimony of Robinson, a Black man, as credible simply because of his race. Fricker maintains that a credibility deficit based on identity prejudice results in the target being treated as an object in the sense of being denied status as someone who is able to be an agent capable of having an active effect on listeners.

Portending a major limitation of Fricker's project, Gaile Pohlhaus, Jr. argues that the point is not that Robinson is perceived as an object when his testimony is dismissed on the basis of identity prejudice. ${ }^{9}$ Rather, he is treated as a truncated subject whose credibility is selectively affirmed or denied depending on whether it conforms to the dominantly situated knower's framework. Anything the target might try to express that is beyond dominant epistemic frameworks is unrecognized and not given uptake. When the speaker's words challenge dominant frameworks of intelligibility, the hearer either dismisses what is said or reshapes and misinterprets what is said in ways that fit the dominant framework. The speaker's epistemic, agential ability to affect and possibly change what the hearer thinks becomes moot.

Pohlhaus' insight underscores that while testimonial injustice harms the speaker in her capacity as a knower, it also has consequences for the silencer. Testimonial injustice curtails what one can hear. Evidence, opposing ideas, and new concepts that are conducive to knowledge expansion can be ignored. Ignorance is maintained by testimonial injustice, and epistemic exclusions result in deficiencies in social knowledge.

Anger is one effect of testimonial injustice. In the face of being persistently ignored and dismissed, rage can be a justified response. Yet there are consequences to expressing anger in that anger can become further justification for being ignored. In her examination of anger, Sara Ahmed explains that when women of color are read as being against $\mathrm{x}$ because one is angry rather than being angry because one is against $x$, they become entangled in their anger and angry at not being heard. This then has been used to provide validation for the dismissal by confirming that only anger grounds the truth behind their speech. ${ }^{10}$ 
An alternative response to testimonial injustice is intimated in Kristie Dotson's discussion of two types of silencing: testimonial quieting and testimonial smothering. ${ }^{11}$ Testimonial quieting occurs when, because of identity prejudice, the hearer does not regard the speaker as a knower or source of knowledge. Because the speaker is not given the appropriate uptake, it is as if the speaker did not speak at all. For example, it is not just that Tom Robinson's testimony endures credibility deficit but, rather, that it means nothing to the jury. On the other hand, if a speaker recognizes that her words are unlikely to receive uptake whether because the hearer is unable or unwilling, she may decide to self-censor or refuse to speak at all. Dotson refers to this as testimonial smothering; the speaker berself withholds testimony. As Dotson points out, such self-censoring arises because one anticipates that one's words will not receive uptake, it is a form of coerced self-silencing. Testimonial quieting and testimonial smothering go hand in hand, for when one is consistently refused uptake, self-censoring and withdrawal become a form of self-care and survival.

Hermeneutical injustice, Fricker's second type of epistemic injustice, occurs because "the powerful have an unfair advantage in structuring collective social understandings" 12 and this results in a lacuna (a gap) in the conceptual or linguistic resources of a society. I want to highlight that Fricker acknowledges that dominant hermeneutical resources exclude concepts that explain marginalized experience. Yet, at the same time, she equates such dominant frameworks with "collective hermeneutical resources" or the shared concepts that are available to understand the social world.

According to Fricker, the absence of a concept to name an injustice results in marginalized knowers not being able to understand or articulate what is happening to them because the language people use shapes how people make sense of their experiences. Significantly, Fricker attributes this lacuna to a structural identity prejudice in the collective hermeneutical framework. ${ }^{13}$ If there is a lack of concepts in the collective hermeneutical resources to name injustice and the reason for this is structural identity prejudice, then marginalized knowers do not have available to them the appropriate interpretative tools 
to understand and communicate marginalized experience.

Although the lacuna exists for all knowers, it does not manifest as injustice for dominantly situated knowers who find a fit between their experiences and the dominant resources available. If a lacuna were to exist, it would not be the result of structural injustice that is based on the dominant knower's social identity.

As an illustration of hermeneutical injustice, Fricker offers that before the term sexual harassment entered our public language, it was challenging for women to understand and name their experience of unwanted sexualized attention because their experience was rendered unintelligible due to gaps in the shared epistemic resources.

\section{WILLFUL IGNORANCE}

There has been an upsurge of scholarship exposing a lacuna in Fricker's own construal of hermeneutical injustice. Because Fricker mistakenly associates dominant frameworks of intelligibility with the available collective hermeneutical resources, she fails to consider other frameworks of intelligibility that might be available to the marginalized but not collectively recognized or even defiantly excluded by dominant frameworks. There is a hidden assumption in Fricker's description of hermeneutical injustices implying that if there are no epistemic resources in dominant frameworks of intelligibility (the collectively shared framework), then the marginalized will lack an understanding of their own experience.

As Rebecca Mason, Jose Medina, Gaile Pohlhaus, Jr., and Kristie Dotson have shown, the marginalized often develop their own epistemic resources, concepts that make their experience intelligible amongst themselves. ${ }^{14}$ The actual problem is that even when the marginalized possess these concepts to name their experiences they may "still remain systematically misunderstood by others...when they try to communicate about those experiences." 15 This critique is significant because not only does it point to a limitation of Fricker's account but it also shifts attention away from an exclusive focus on implicit 
identity bias and, instead, draws attention to willful ignorance, a refusal to engage with resources that make sense of marginalized experience

Dotson maintains that Fricker contends that both the marginalized speaker and the dominant hearer have equal difficulty in making marginalized experience intelligible because she assumes there is only a single group of collective hermeneutical resources available to all. ${ }^{16}$ As Dotson insists, this fails to take into account alternative epistemologies developed by marginalized communities that explain the injustice they endure but that are not only widely rebuffed by dominantly situated knowers but also willfully resisted by them.

The marginalized may very well understand their experiences and have their own epistemic resources that make their experiences intelligible. Pohlhaus adds that dominantly situated knowers pre-emptively dismiss such epistemic resources and introduces the concept of "willful hermeneutical ignorance" which occurs "when dominantly situated knowers refuse to acknowledge epistemic tools developed from the experienced world of those situated marginally." ${ }^{1718}$ This refusal to engage allows the systemically privileged to "misunderstand, misinterpret, and/or ignore whole parts of the world" 19 and it preserves the comfort of ignorance.

Moreover, Pohlhaus notes that despite the existence of the term sexual harassment to name such oppression, some men will still dismiss its legitimacy or mock women who use the term to explain their experience. Such men's refusal to know often manifests in blaming women for lacking a sense of humor or being too sensitive. The dominant positionality of such men allows them to deny credibility to the concepts that make sense of such experiences. In other words, the concepts are available to understand marginalized experience but often not used because of credibility access and an exclusive adherence to dominant frameworks of intelligibility. These men protect their dominance by "not enter(ing) into a relation of true epistemic interdependence" ${ }^{20}$ with the women who need this concept to explain their experience. While Fricker focuses on credibility deficit and contends that credibility excess does not constitute epistemic injustice, Pohlhaus demonstrates how dominantly situated knowers place too much confidence in their own experiences and 
interpretations of events and, thereby, cannot "hear" conflicting, but relevant, interpretations provided by the marginalized.

Epistemic injustice thus involves more than just implicit bias or lack of concepts for the marginalized to explain their experiences to themselves. Fricker's focus on implicit identity bias implies that if one just brings implicit bias to awareness, it will be extinguished. This ignores the resilience both of dominantly situated knowers' refusal to know as well as the closed character of dominant systems of meaning that contain the "seeds of their own preservation," 21 examples of which will be subsequently provided. Dotson captures this when she introduces a third form of epistemic injustice. "Contributory injustice" underscores the persistent deference to dominant hermeneutical resources that prevents the proper uptake of the resources that the oppressed have developed to make sense of their experience. ${ }^{22}$

The emphasis on "contributory" highlights that this type of injustice involves the marginalized not being able to contribute the concepts necessary to explain their experience to the collective understanding. The focus on "contributory" also makes clear that this is not due to their not having a contribution to make but, rather, because their contributions are systematically dismissed by dominantly situated knowers. Therefore, "contributory" also underscores the ways in which the systemically privileged are actively and collectively complicit in blocking the conceptual resources that are crucial for understanding marginalized experience from mainstream discourse. Attempts by the systemically marginalized to "prove" the pervasiveness of patterns of sexism and racism, for example, become tiresome and fruitless because there is no uptake or engagement.

In his discussion of white ignorance, Charles Mills argues that such ignorance is not merely a passive lack of knowledge on the part of the individual but an active distancing from what one does not want to know that has an entire battery of systemically supported defense mechanisms that shield such ignorance from challenge. ${ }^{23}$ Unlike traditional understandings of ignorance which consider ignorance as individual deficiency, Mills maintains that white ignorance is a form of systemically sustained ignorance that is "militant, aggressive, not at all 
confined to the illiterate and uneducated but propagating at the highest levels of the land, indeed presenting itself unblushingly as knowledge." ${ }^{24}$ Linking white ignorance to the maintenance of white supremacy, Mills explains that dominant racial epistemic structures support "a particular pattern of localized and global cognitive dysfunctions (which are psychologically and socially functional)" that protect the privileges of the racially dominant group and shield such privileges from contestation. ${ }^{25}$

Building and expanding upon Mills' work, Jose Medina describes a type of active ignorance that is associated with "cognitive comfort" and manifests in a refusal to believe that impedes learning and epistemic growth. ${ }^{26}$ Active ignorance protects comfortable certainties and "is a form of insensitivity that filters out experiences that can challenge our beliefs and create troubles for our cognitive perspective." ${ }^{27}$ Medina introduces the concept of meta-ignorance to explain how bodies of ignorance remain resistant to change. Such ignorance entails an ignorance of one's own ignorance that ensures that dominantly situated knowers will not have to recognize how they are implicated in the perpetuation of unjust systems. This is another indication that dominant systems of meaning contain the seeds of their own preservation. Mega-ignorance involves not only not knowing and not needing to know but, more significantly, needing not to know. For Medina, meta-ignorance entails an active effort to avoid what he refers to as "epistemic friction." Medina offers an analysis of colorblindness or the refusal to consider social positionality as an illustration of such avoidance of conflict and friction.

The point here is not that epistemic justice requires the uncritical acceptance of the testimony of the marginalized ${ }^{28}$ but, rather, to expose the ways in which dominantly situated knowers have the "privilege" to immediately doubt and dismiss the marginalized speaker's testimony in ways that seem "reasonable." Meta-ignorance helps to bring an important feature of contributory injustice into clearer view because it not only reveals the self-confidence of individuals who do not know that they do not know and do not need to know marginalized truths but think they know, but it also highlights how dominantly-situated knowers need not to know because to genuinely engage in such 
knowledge would threaten their epistemic comfort. Moreover, it underscores the deeply built-in preserving mechanisms that impede any attempt to challenge the authority of dominant frameworks of intelligibility.

The willfulness of willful ignorance now comes into sharper focus. Willfulness is not necessarily an intentional act of unwillingness, although it could be. Willful ignorance can be a tenacious refusal that does not seem like a refusal at all because it is buttressed by dominant epistemic frames. It is willful because it preserves comfort. Moreover, meta-ignorance as a form of willful ignorance is often maintained under the guise of objectivity, rationality and universality. In an excellent illustration of how dominant systems of meaning contain the seeds of their own preservation, Kristie Dotson demonstrates how there are "difficult-to-defeat arguments concerning the 'legitimacy' of police slayings against Black people" grounded in what she refers to as "resilient oblivion" and "which can have the effect of normalizing oppressive conditions." 2930 Although space restrictions prevent me from analyzing Dotson's argument in detail, her critical deconstruction of the rationalization of police brutality against Black bodies as a reaction to "reasonable threat" is a remarkable illustration of both willful ignorance and how patterns of oppressive events are recast as "reasonable."

Medina concludes that meta-ignorance is the ultimate source of hermeneutical and testimonial injustice. More than prejudice or implicit bias, it is dominant group members' denial of credibility to (and refusal to engage with) the frameworks of intelligibility that the marginalized offer that supports epistemic injustice and shields such injustice from challenge, a point that Fricker's limited focus occludes.

\section{EPISTEMIC EXPLOITATION}

A compelling demonstration of how willful ignorance can hide behind good intentions and contribute to RBF is found in what Nora Berenstain refers to as "epistemic exploitation." ${ }^{31}$ Epistemic exploitation names the widespread experience (especially in academia) of systemically privileged individ- 
uals expecting marginalized individuals to educate them about white privilege and the experience of oppression. Berenstain points to the ways in which such exploitation masquerades as epistemically virtuous forms of intellectual engagement-a pursuit of truth, a harmless exercise of curiosity, just wanting to know-but, in effect, such expectations are an abuse of marginalized people's labor. In addition, when the systemically privileged demand to be educated but then fail to utilize and seriously engage with what they are told, the epistemic harms of willful ignorance are intensified and also dominant epistemic frameworks are protected from challenge-all under the guise of the pursuit of knowledge.

These two related aspects of epistemic exploitation deserve emphasis. First, there is the unremunerated labor that the marginalized are expected to provide in order to educate the systemically privileged about systems of privilege and oppression. This keeps the marginalized busy with the needs and interests of the systemically privileged while their own needs and academic interests are ignored. Second, in characterizing this labor, Berenstain draws attention not only to the labor of educating but also to the challenge that the marginalized face in response to the testimony they offer. Berenstain refers to the "default skepticism of the privileged" where the testimony of the marginalized is not only responded to with suspicion but that, in the eyes of the skeptic, such skepticism is taken to be legitimate objections and even evidence of the skeptic being engaged and open-minded. ${ }^{32}$ In light of these ostensibly good intentions, the marginalized are forced into a dilemma-try harder to educate and endure the emotionally exhausting attempts to constantly justify and substantiate what one knows to those who do not have "the ears to hear" or be labeled negatively. ${ }^{33}$ As Alison Jones so powerfully demonstrates, when the marginalized refuse to educate, white students label them as the problem. ${ }^{34}$ Dominant knowers, in addition, do not only deny credibility to members of marginalized groups but they also demand information from the marginalized which they then doubt in a way that keeps the rules of the game in dominantly situated knowers' hands.

These skeptical attitudes are a manifestation of willful ignorance and 
contribute to racial battle fatigue. Saba Fatima describes an experience that she encountered as a teaching assistant. She ran into one of her students in the library who was studying for the final exam. The student was clearly anxious and in her attempt to calm her student's angst about the final, Fatima tells the student that she saw the exam and it's not that bad. Another white male student standing nearby who was not in Fatima's section and overheard the conversation, calls out to Fatima in a terse command, "Hey!...Come here." As a petite, woman of color and an advanced doctoral candidate the white male's student snippy tone felt jarringly disrespectful. ${ }^{35}$

The point that Fatima wants to accentuate, however, is the epistemic violence she encounters when she tries to explain to her colleagues why she felt so disrespected by the student's demand. Her explanations are dismissed or reframed in ways that not only disregard her interpretation of her experience but in ways that sound "reasonable." Fatima narrates that she is given advice such as "Be rational, be reasonable, the student didn't mean it that way," or "Be strong, don't make such a big deal out of something so trivial." Therefore, a common response of white people upon hearing about racially oppressive experiences is to offer alternate and "reasonable" explanation of what actually happened. The implication is that the speaker does not know how describe his/her/their reality. ${ }^{36}$

Fatima explains how these seemingly well-meaning and seemingly reasonable counsels push her to the edge of knowing and contribute to her questioning the reality she herself knows. Moreover, if she allows herself to express justified anger then she is tone-policed and charged with "incivility." The demand for civility can function as a tool to silence those who raise issues that dominantly situated knowers refuse to hear. As previously noted, Sara Ahmed discusses how this cycle of dismissal works and the way in which expressed anger is used to further dismiss what the marginalized are saying.

Your reasonable...arguments are dismissed as anger (which of course empties anger of its own reason), which makes you angry, such that your response becomes read as the confirmation of the evidence that you are not only angry 
but also unreasonable! $!^{37}$

Willful ignorance — a refusal to seriously engage with marginalized epistemic frameworks-plays a major part in the cycle that contributes to doubt and paranoia. Fatima notes that

we...become unsure... and lose epistemic ground with each passing moment because no one around us saw it the same way. ${ }^{38}$

When Fatima contends that epistemic injustice pushes her to the edge of her ability to know, it is a clear sign of racial battle fatigue.

Given the epistemic costs of racial battle fatigue, silence and retreat can be an intentional and understandable response. In her provocatively titled book, Why I'm No Longer Talking to White People About Race, Reni Eddo-Lodge describes how white people utilize numerous counter-arguments to deny what she says about her experience as a Black woman. ${ }^{39}$ Eddo-Lodge declares that she was no longer talking to white people about race since she no longer wanted to engage with the emotional disconnect displayed by white people when she attempts to articulate her experience. Withdrawing from hostile spaces is a way to enact her sense of agency and also is a form of self-survival.

A similar decision to disengage is evident in the example Dotson offers to illustrate epistemic smothering. Dotson refers to a 1996 article by Cassandra Byers Harvin titled, "Conversations I Can't Have," in which Harvin describes her need to avoid conversations about race with her white friends and colleagues because she can no longer deal with their hurt, surprise and defensiveness. ${ }^{40}$ Harvin relates an experience she had with a white woman in the public library who asked Harvin what she was working on. When Harvin explains that she is doing research on "raising black sons in this society" the white woman promptly inquires, "How is that any different from raising white sons?" 41 As Harvin relates the encounter she underscores that the white woman's question not only expressed a level of ignorance of the difficulties of raising a Black son in a white supremacist society but also that the tone, the skeptical manner, with which the question was framed implied in a condescending 
way that Harvin is "making something out of nothing." 42 Harvin chooses not to engage with the white woman and politely makes up an excuse that she is late and needs to leave the library — this was a conversation she could not have.

\section{IMPLICATIONS FOR EDUCATION}

Dialogue around racial injustice in the academic classroom can be a precarious for students of color. Zeus Leonardo and Ronald Porter expose the myth of safe spaces and argue that when it concerns public race dialogue, students of color are almost never safe. They describe the dilemma that students of color find themselves as standing "between the Scylla of becoming visible and the Charybdis of remaining silent." ${ }^{4344}$

Similarly, Deanna Blackwell critiques typical forms of anti-racist education for assuming that the role of students of color in the classroom will be as cultural experts, the teacher's aide and the witness of white epiphanies. ${ }^{45}$ Such expectations prioritize the interests of white students while the academic needs of students of color are ignored. Alison Jones asks: For whose benefit is dialogue across difference? Both Blackwell and Jones advocate for the value of separate spaces for students of color on predominantly white campuses.

As a white educator who teaches courses about social justice, I have had racially marginalized students walk out of my not-so-safe class in frustration with white students' fragility and my inadequate attempts to disrupt it. ${ }^{46}$ And while I once believed that I am promoting my students of color's epistemic agency by assuming they want be in the position of educator in the classroom, I have since learned that they may understand this role as exploitive. They not only have to endure the white students' defensiveness and resistance and also to be put in the position of having to absolve white students' guilt but, in addition, as the professor, I get the credit of creating a space where white students can discuss difficult issues. My own white fragility is manifest when I remember the discomfort and insecurity I experienced as an educator when these students walked out because, as I now understand, their withdrawal denies me the "good-feeling rewards" of teaching. Instead, I have learned to 
stay in the moment of discomfort by asking myself: How is willful ignorance circulating in my classroom? How am I contributing to the epistemic harms of my students of color by burdening them with the expectation that will play a certain role in cross-racial dialogue? How am I ignoring their needs and interests?

The epistemic harms that students of color bear in mixed race classrooms must be acknowledged and the ways in which white willful ignorance contributes to such harms must be disrupted. In his discussion of meta-ignorance, Medina recommends that dominantly situated knowers learn how to stay in the discomfort of "epistemic friction." In order to unsettle the protective mechanisms of ignorance, Medina notes that it is important to "make painfully visible the price of epistemic comfort under conditions of oppression, so that people cannot avoid the realization that the comfort of some comes at the cost of the discomfort of others." ${ }^{\prime 47}$ Willful ignorance, rather than implicit bias, can help educators to understand the epistemic harms that racially marginalized students endure engaging in dialogue around racial injustice. In order to avoid or limit epistemic exploitation, dominantly situated knowers, students, and educators must be encouraged to ask: What don't I know? What don't I need to know? What don't I want to know and why?

While a better understanding of willful ignorance can lead to understanding the violence that students of color can experience in cross-race dialogues, there is some flicker of hope in Pohlhaus' comment that "the solution is not to give something to the marginally situated knower such as credibility or epistemic resources...the solution is for dominantly situated knowers to catch up and learn to use epistemic resources they lack by forging truly cooperative interdependent relations with marginally situated knowers." ${ }^{38}$ Shifting the focus from implicit bias to willful ignorance in social justice pedagogy, I have argued, can be one tool that may help forge such cooperative and interdependent relations.

1 William A. Smith, "Higher Education: Racial Battle Fatigue," in Encyclopedia 
of Race, Ethnicity, and Society, ed. R. T. Schaefer (Thousand Oaks, CA: Sage, 2008), 615-618, 617.

2 Willian A. Smith, Tara Yosso, and David Solorzano, "Challenging Racial Battle Fatigue on Historically White Campuses: A Critical Race Examination of Race-related Stress," in Faculty of Color Teaching in Predominantly White Colleges and Universities, ed. C. A. Stanley (Bolton, MA: Anker, 2006), 299-327. 3 Saba Fatima, "I Know What Happened to Me: The Epistemic Harms of Microaggressions," in Microaggression and Philosophy, eds. L. Freeman and J. Weekes Schroer (New York: Routledge, 2020), 163-183, 166.

4 Miranda Fricker, Epistemic Injustice: Power and the Ethics of Knowing (Oxford: Oxford University Press, 2007).

5 Nora Berenstain, “Epistemic Exploitation,” Ergo: An Open Access Journal of Philosophy 3, no. 22 (2016): 569-590.

6 Lorraine Code, Rhetorical Spaces: Essays on Gendered Locations (London: Routledge, 1995); Patricia Hill Collins, Black Feminist Thought: Knowledge, Consciousness, and the Politics of Empowerment (London: Routledge, 1990); Linda Alcoff and Elizabeth Potter, eds., Feminist Epistemologies (New York: Routledge. 1993). 7 Fricker, Epistemic Injustice, 1.

8 Harper Lee, To Kill a Mockingbird (Philadelphia, PA; Lippincott, 1960).

9 Gaile Pohlhaus, Jr., "Discerning the Primary Epistemic Harm in Cases of Testimonial Injustice," Social Epistemology 28, no. 2 (2014): 99-114.

10 Sara Ahmed, The Promise of Happiness (Durham, NC: Duke University Press, 2010), 68.

11 Kristie Dotson, "Tracking Epistemic Violence, Tracking Practices of Silencing," Hypatia 26, no. 2 (2011): 236-257. 
12 Fricker, Epistemic Injustice, 147.

13 Fricker, 155.

14 Jose Medina, "Hermeneutical Injustice and Polyphonic Contextualism: Social Silences and Shared Hermeneutical Responsibilities," Social Epistemology 26, no. 2 (2012): 201-220; Gaile Pohlhaus, Jr., "Relational Knowing and Epistemic Injustice: Toward a Theory of Willful Hermeneutical Ignorance," Hypatia 27, no. 4 (2012): 715-735; Kristie Dotson, “A Cautionary Tale: On Limiting Epistemic Oppression," Frontiers: A Journal of Women Studies 33, no. 1 (2012): 24-47; Rebecca Mason, "Two Kinds of Unknowing," Hypatia 26, no. 2 (2011): 294-307. I want to note that in more recent work, Fricker has acknowledged the significance of both Pohlhaus' and Dotson's critique. See Miranda Fricker, "Evolving Concepts of Epistemic Injustice," in The Routledge Handbook of Epistemic Injustice, eds. J. Kidd, J. Medina, and G. Pohlhaus (New York: Routledge, 2017), 53-60.

15 Medina, "Hermeneutical Injustice and Polyphonic Contextualism," 207. 16 Dotson, "A Cautionary Tale."

17 Pohlhaus, Jr., "Relational Knowing and Epistemic Injustice."

18 Pohlhaus, Jr., 715.

19 Pohlhaus, Jr., 716.

20 Pohlhaus, Jr., 726.

21 Alison Bailey, “The Unlevel Knowing Field: An Engagement with Dotson's Third-Order Epistemic Oppression," Social Epistemology Review and Reply Collective 3, no. 10 (2014): 62-68, 66.

22 Dotson, "A Cautionary Tale."

23 Charles Mills, "White Ignorance," in Race and Epistemologies of Ignorance, eds. 
Shannon Sullivan and Nancy Tuana (Albany, NY: State University of New York Press, 2007): 13-38.

24 Mills, "White Ignorance," 13.

25 Mills, 18.

26 Jose Medina, The Epistemology of Resistance: Gender and Racial Oppression, Epistemic Injustice, and Resistant Imaginations (New York: Oxford University Press, 2013); Jose Medina, “On Refusing to Believe: Insensitivity and Self-Ignorance," in Rationality Reconsidered: Ortega y Gasset and Wittgenstein on Knowledge, Belief, and Practice, eds. José María Ariso and Astrid Wagner (Berlin: De Gruyter, 2016): 187-200.

27 Medina, “On Refusing to Believe,” 192.

28 This is a topic I hope to take up in a future project.

29 Kristie Dotson, “Accumulating Epistemic Power: A Problem with Epistemology," Philosophical Topics 46, no .1 (2018): 129-154.

30 Dotson, “Accumulating Epistemic Power," 129.

31 Nora Berenstain, "Epistemic Exploitation."

32 Berenstain, 578.

33 Alison Jones, “The Limits of Cross-Cultural Dialogue: Pedagogy, Desire, and Absolution in the Classroom," Educational Theory 49, no. 3 (1999): 299-316, 308.

34 Jones, "The Limits of Cross-Cultural Dialogue," 308.

35 Saba Fatima, "On the Edge of Knowing: Microaggressions and Epistemic Uncertainty as a Woman of Color," in Surviving Sexism in Academia: Feminist Strategies for Leadership, eds. Kirsti Cole and Holly Hassel (New York: Routledge 2017), 147-154 
36 Fatima, "On the Edge of Knowing," 152.

37 Sara Ahmed, The Promise of Happiness, 68.

38 Fatima, "On the Edge of Knowing," 148.

39 Reni Eddo-Lodge, Why I'm No Longer Talking to White People About Race (New York: Bloomsbury, 2017).

40 Cassandra Byers Harvin, "Conversations I Can't Have," On the Issues 5, no. 2 (1996): 15-16.

41 Harvin, “Conversations I Can’t Have," 16.

42 Harvin, 16.

43 Zeus Leonardo and Ronald K. Porter, "Pedagogy of Fear: Toward a Fanonian Theory of 'Safety' in Race Dialogue,' Race, Ethnicity and Education 13, no. 2 (2010): 139-157.

44 Leonardo and Poter, "Pedagogy of Fear," 140.

45 Deanna Blackwell, "Sidelines and Separate Spaces: Making Education Anti-Racist for Students of Color," Race, Ethnicity and Education 13, no. 4 (2010): 473-494.

46 Robin DiAngelo. "White Fragility," International Journal of Critical Pedagogy 3, no. 3 (2011): 54-70.

47 Medina, “On Refusing to Believe," 197.

48 Pohlhaus, Jr., "Relational Knowing," 733. 